\title{
Research on market orientation: Some lessons shared and issues discussed in a doctoral seminar
}

\author{
Rajan Varadarajan ${ }^{1}$
}

Received: 6 March 2017 / Accepted: 10 May 2017 / Published online: 6 June 2017

(C) Academy of Marketing Science 2017

\begin{abstract}
For more than a quarter of a century, a large body of research in marketing, as well as in other disciplines, has focused on a number of substantive, theoretical and methodological issues relating to market orientation. Reflecting on their market orientation focused research journey, Jaworski and Kohli (2017) offer 22 valuable lessons for researchers on the nuances of conducting field-based, discovery-oriented research. For over two decades, market orientation has been among the substantive topics on the syllabus of a doctoral seminar on strategic marketing that I have taught at Texas A\&M University. Over the years, I have greatly benefited from reading a number of journal articles on market orientation, in preparing for the seminar session on market orientation. Reflecting on the insights gained from this learning journey, I elaborate on five lessons shared, and five issues discussed in the seminar.
\end{abstract}

Keywords Market orientation - Customer orientation . Competitor orientation $\cdot$ Market oriented behavior $\cdot$ Market orientation culture

Through their pioneering and programmatic research on market orientation, Jaworski and Kohli (J\&K) have had a major and enduring impact on scholarly research in marketing, marketing education, and marketing practice. One indicator of the impact of their contributions to the market orientation literature on research in marketing are the following Google Scholar citation metrics for their first three articles on the topic: Kohli and Jaworski (1990) - over 9750 citations.

Rajan Varadarajan

varadarajan@tamu.edu

1 Department of Marketing, Mays Business School, Texas A\&M University, 4112 TAMU, College Station, TX 77843-4112, USA
Jaworski and Kohli (1993) - over 8500 citations. Kohli et al. (1993)- over 2600 citations. ${ }^{1}$ As a measure of research impact, in the marketing discipline, three journal articles with a combined citation of over 20,000 is indeed impressive.

Reflecting on their research journey investigating important substantive questions pertaining to market orientation, Jaworski and Kohli (2017) offer 22 valuable lessons for researchers on the nuances of conducting field-based, discovery-oriented research. Since 1982, every alternate year, I have taught a doctoral seminar on strategic marketing at Texas A\&M University. For over two decades, market orientation has been an integral part of the seminar. When I offered the seminar in 1992, two articles on market orientation were on the syllabus (Kohli and Jaworski 1990; Narver and Slater 1990). As the body of published research on the topic grew, so did the number of articles on the syllabus, and the class time devoted to discussion of issues relating to market orientation (from about an hour during a three hour session, to the entire session). Every alternate year, in preparing for the seminar session on market orientation, I have greatly benefited from reading a number of journal articles on market orientation. Reflecting on the insights gained from this learning journey, in this article, I elaborate on five lessons shared, and five issues discussed in the seminar over the years.

The potential (actual) contributions of a journal article can be broadly stated (assessed) form the standpoint of its implications for (impact on) marketing practice, research in marketing, marketing education, and public policy. A cursory review of journal articles addressing marketing issues with a managerial focus would reveal that the scope of the "Implications" section is generally limited to "implications for marketing practice," and "implications for future research." However, in this article, I focus on the impact of published research on market orientation on marketing education at the

\footnotetext{
${ }^{1}$ As of May 21, 2017.
} 
doctoral level (albeit, in a very limited context - the doctoral seminar related experiences of $a$ marketing educator).

The article is organized into two major sections. The first section focuses on some research, publishing and crafting of manuscript related lessons (insights or takeaways) gleaned from J\&K's seminal articles on market orientation (Kohli and Jaworski 1990; Jaworski and Kohli 1993; Kohli et al. 1993), that I have highlighted to the class. It's conceivable that some readers may view these lessons as too elementary. It should, however, be borne in mind that these were highlighted as research, publishing and crafting of manuscript related lessons or takeaways to first and second year doctoral students. The second section focuses on certain broader issues around which I have attempted to have a discussion during the seminar session on market orientation. These are in the context of the larger body of literature on market orientation, and not limited to J\&K's above articles on market orientation. ${ }^{2}$ The sections that follow on lessons shared and issues discussed are presented in the style of a journal article. Illustrative examples of how these were shared and discussed in class are presented in Footnotes 4 and 5, respectively.

\section{Lessons shared}

\section{Lesson \# 1: Impactful research elevates the level of discourse on a substantive topic from a slogan to a science}

'Moving "Customer Satisfaction" from a Slogan to a Science' is the title of a chapter in the book, "Managing Customer Value: Creating Quality and Service That Customers Can See," by Gale (1994). J\&K's articles on market orientation (Kohli and Jaworski 1990; Jaworski and Kohli 1993: Kohli et al. 1993) exemplify programmatic research that elevated the level of discourse on market orientation from the level of a slogan (unsubstantiated assertions, observations, points-of-view, prescriptions and statements such as "firms should be more market oriented," and "being more market oriented is key to becoming more profitable) to a science by addressing some very fundamental questions such as the following:

- Definition and delineation of the construct: What is market orientation? [A 1988 article titled, "What the Hell is Market-Oriented" (Shapiro 1988) serves to highlight the state-of-knowledge (e.g., lack of clarity over even the meaning of the term, "market orientation") prior to Kohli and Jaworski (1990)].

\footnotetext{
${ }^{2}$ Not all of the five lessons shared and five issues discussed were covered during the seminar session on market orientation, every time I taught the seminar. Given the interactive nature of the learning environment in a doctoral seminar, often, the air time available for the instructor to share her/his thoughts is: "Total air time available (duration of the class session) minus air time taken up by the students."
}

- Operationalization and measurement of the construct: What would constitute a valid and reliable scale for operationalizing the proposed definition of market orientation - measuring the amount of a specific property (market orientation) in a population of objects (businesses)?

- Antecedents of market orientation and moderators of the relationship: What explains variance in market orientation? When (under what organizational and environmental conditions) are businesses likely to be more versus less market oriented, and why?

- Performance consequences of market orientation and moderators of the relationship: What is the nature of the relationship market orientation and business performance? When (under what organizational and environmental conditions) is market orientation likely to be more versus less conducive to enhancing business performance, and why?

- What are the implications of the research findings for future scholarly research in marketing and marketing practice?

\section{Lesson \# 2: Communicating a comprehensive network of relationships with clarity may require use of multiple interlinked figures}

Kohli and Jaworski (1990) present their conceptual model of market orientation using four inter-linked figures. In Fig. 1, they present the overarching conceptual model delineating the antecedents and outcomes of market orientation. In Figs. 2, 3 and 4, they provide an in-depth of exposition of the relationship between market orientation and specific sets of antecedent factors (Fig. 2: Senior Management Factors. Fig. 3: InterDepartmental Dynamics. Fig. 4: Organizational Systems). When asked to imagine a conceptual model in which Figs. 1 to 4 are collapsed into a single figure, the students develop an appreciation of the merits of using multiple, inter-linked frameworks in order to communicate with clarity a comprehensive set of inter-relationships.

\section{Lesson \# 3: Disseminating the findings of a large research project in a series of articles requires giving careful thought to the objectives and scope of individual articles}

In an article focusing on some uncertainties surrounding research and publishing, Graham and Stablein (1985) pose and address a number of questions including the following: (1) how to envision the publishable outcomes of a research effort in advance, (2) how to carve up a large research project into separate pieces, and (3) how much is enough for a given article, and what to include and what not to include in it. The following articles on market orientation by J\&K serve as an excellent illustration of an answer to the above questions: 
1. Market Orientation: The Construct, Research Propositions and Managerial Implications (Kohli and Jaworski 1990)

2. Market Orientation: Antecedents and Consequences (Jaworski and Kohli 1993)

3. MARKOR: A Measure of Market Orientation (Kohli et al. 1993)

The first article, by synthesizing insights from literature and theories in use, provides a conceptualization and definition of the focal construct (market orientation) and a conceptual model (antecedents and outcomes of market orientation). The second article reports the findings of the empirical test of the model, and implications for research and practice. The third article presents an in-depth discussion on the multi-item scale developed for measurement of market orientation that was employed in the second article (i.e., scale development process, results of tests of scale validity and reliability, etc.).

Over the years, in preparing for the seminar session on market orientation, I have read some of J\&K's articles on market orientation (e.g., Kohli and Jaworski 1990; Jaworski and Kohli 1993: Kohli et al. 1993) several times. As a result, even minor commissions and omissions in their works have caught my attention and turned out to be of value as lessons to share. Lessons \# 4 and 5 that follow are cases in point.

\section{Lesson \# 4: Review scale items for words that may be difficult to translate into other languages}

Another indicator of the impact of J\&K's research on market orientation, is research conducted in some other parts of the world and disseminated through journals published in other languages (e.g., Chung and Jang 2003; Kang et al. 2011). In this regard, a lesson or takeaway stems from the following scale item that Jaworski and Kohli (1993, p. 68) use to measure competitive intensity: "Competition in our industry is cutthroat." To researchers attempting to translate the above scale item into another language, the word "cutthroat" may present a challenge. To the extent possible, it may be desirable to avoid the use of colloquial words in scale items.

\section{Lesson \# 5: Review manuscript for alignment between various sections}

As manuscript authors (reviewers), we are coached (expected) to carefully review manuscripts to ensure that the various sections are in alignment. For example: (1) research questions and hypotheses, (2) conceptual model and hypotheses, (3) conceptual model and hypotheses and research design, (4) research questions and research findings, and (5) research findings and implications. As a reviewer, over the years, I have been privy to a number of papers with alignment problems in one or more of the above areas. For example, lack of alignment between (1) research questions and hypotheses (i.e., empirical testing of the hypotheses will not provide answers to the research questions); and (2) conceptual model and hypotheses (i.e., absence of formal hypotheses statements and supporting conceptual rationale for some of the relationships delineated in the conceptual model; or, failure to delineate in the conceptual model some of the relationships that are formally stated with supporting conceptual rationale). ${ }^{3}$

In Jaworski and Kohli (1993, p. 56), $\mathrm{H}_{5}, \mathrm{H}_{6}$ and $\mathrm{H}_{7}$ are stated as follows:

$\mathrm{H}_{5}$ : The greater the formalization, (1) the lower the intelligence generation, dissemination and response design, and (2) the greater the response implementation.

The greater the centralization, (1) the lower the intelligence generation, dissemination and response design, and (2) the greater the response implementation.

$\mathrm{H}_{7}$ : The greater the departmentalization, (1) the lower the intelligence generation, dissemination and response design, and (2) the greater the response implementation.

In reference to $\mathrm{H}_{5}$ through $\mathrm{H}_{7}$, in the "Analysis and Results" section, Jaworski and Kohli (1993, p. 61) rightly note: "Additionally, $\mathrm{H}_{5}$ through $\mathrm{H}_{7}$ hypothesized opposite effects of formalization, centralization, departmentalization on the two components of responsiveness - response design and response implementation. Accordingly, two additional regression equations were estimated by incorporating response design and response implementation as the dependent variables and the eight independent variable previously noted. The results of formalization, centralization, and departmentalization on the two components of responsiveness in both samples were identical to those obtained for the overall responsiveness reported in Tables 1 and 2."

The above, I have highlighted in the class as an example of due diligence in ensuring alignment between hypotheses and analysis. At the same time, I have also drawn to the attention of the class the lack of alignment between a hypothesis $\left(\mathrm{H}_{6}\right)$ and the standardized regression coefficient reported for the hypothesis (see: Jaworski and Kohli 1993; Table 1, p. $61 ;-0.22 ;<.01)$. Given the hypothesized opposite effects for centralization in $\mathrm{H}_{6}$ for the two components of responsiveness (greater the centralization, the lower the response design; greater the centralization, the greater the response implementation), no inference regarding either support for these hypotheses, or lack thereof, can be made based on the significant standardized

\footnotetext{
${ }^{3}$ Needless to say, there are likely to be alignment related weaknesses in some of my published research as well.
} 
regression coefficient for overall responsiveness reported in the table. ${ }^{4}$

\section{Issues discussed}

The preceding section focused on some lessons pertaining to research, publishing and crafting of manuscripts gleaned from J\&K's seminal articles on market orientation (Kohli and Jaworski 1990; Jaworski and Kohli 1993; Kohli et al. 1993) that I have shared over the years in my doctoral seminar. This section focuses on certain issues that I have steered the class to discuss, in the context of the larger body of literature (assigned readings) on market orientation. The discussion items enumerated were presented to the class in the true spirit of issues for discussion (issues to reflect upon and share their thoughts, and not evaluate the relevant content in the journal article as either right or wrong).

\section{Discussion item \# 1: Correspondence of conceptualizations and definitions of organizational orientation constructs in literature with the dictionary meaning of "orientation"}

A number of organizational orientation constructs (e.g., competitor orientation, customer orientation, entrepreneurial orientation, innovation orientation, knowledge orientation, learning orientation, market orientation and strategic orientation) are the focus of a large body of research in the marketing and management literature. Table 1 provides an overview of representative conceptualizations and/or definitions of certain constructs that have been advanced in literature. As summarized in the table, these constructs have been conceptualized and/or defined in in literature from various perspectives such as specific behaviors or pattern of behaviors that an organization engages in, an organization's predisposition to engage in specific behaviors or pattern of behaviors, ability and will to engage in specific behaviors, culture, beliefs, understanding, encouragement of specific values, and knowledge structure.

A question that I have posed to the class for discussion is the extent to which conceptualizations and definitions of various organizational orientation constructs correspond with (should be in correspondence with) or deviate from the dictionary meaning of the word "orientation." Consider for instance, the following dictionary meanings of "orientation":

\footnotetext{
${ }^{4}$ In reference to Lesson \# 5, in order to initiate a discussion, I would pose a question to the class along the following lines:

"Based on the significant standardized regression coefficient for overall responsiveness reported in Table 1 in Jaworski and Kohli (1993) $(-0.22$; < .01 ), what inferences would you draw regarding support for the following subhypotheses stated under $\mathrm{H}_{6}$ : (1) the greater the centralization, the lower the response design, and (2) the greater the centralization, the greater the response implementation?"
}

- The direction that any process, movement or development follows. A finding out of the actual facts and conditions and putting oneself in the right relation to them. A general point of view toward a topic or an object. (The World Book Encyclopedia Dictionary 1966; p. 1365).

- The act or process of being oriented. The state of being oriented. Alignment. Arrangement. General or lasting direction of thought, inclination or interest. Change of position in response to external stimulus. (Merriam-Webster's Collegiate Dictionary 2003, p. 875).

Regardless of how "orientation" is construed (e.g., behaviors, beliefs, values), of interest when studying a population of objects (e.g. firms, business units in a multibusiness firm, functional areas in a firm), the subject matter of interest is the amount of a specific property or a set of inter-related properties found evidenced in individual objects that are the focus of the study. As pointed out by Hunt (2012), the use of the word "orientation" in an organizational context implies that a firm is facing toward certain things in the environment, and by virtue of "facing toward" paying more attention to certain issues, problems and opportunities, than to others. Clearly, Kohli and Jaworski's (1990) conceptualization of market orientation (market intelligence generation, dissemination, and responsiveness) is in alignment with a dictionary meaning of orientation (finding out of the actual facts and conditions and putting oneself in the right relation to them). Voss et al.'s (2005) p. 1134) conceptualization of entrepreneurial orientation as a pre-disposition to engage in specific behaviors (pre-disposition rather than actual behaviors) also seems to be in alignment with the dictionary meaning of orientation. However, the conceptualizations and/or definitions of some of the other organizational orientation constructs summarized in Table 1 seem to be somewhat removed from the dictionary meaning of "orientation."

\section{Discussion item \# 2: Definition of market orientation}

Kohli and Jaworski (1990, p.6) define market orientation as "the organization wide generation of market intelligence pertaining to current and future customer needs, dissemination of the intelligence across departments, and organization wide responsiveness to it." As might be noted, in their definition, J\&K circumscribe the scope of market intelligence as intelligence pertaining to the current and future needs of customers. They further note that since organizations are likely to differ in the extent to which they generate market intelligence, disseminate it internally, and take actions based on the intelligence, the market orientation of an organization should be conceptualized as one of degree, rather than as an absolute (i.e., an organization is either market oriented or not market oriented). 
Table 1 Conceptualization and Definition of Organizational Orientation Constructs in Marketing and Management Literature: An Overview ${ }^{\mathrm{a}, \mathrm{b}}$

\section{Construct: Conceptualization and/or Definition}

Remarks

\section{Market Orientation}

"The organization-wide generation of market intelligence pertaining to current and future customer needs, dissemination of the intelligence across departments, and organization-wide responsiveness to it." (Kohli and Jaworski 1990, p. 6)

"The organizational culture that most effectively and efficiently creates the necessary behaviors for the creation of superior value for buyers and, thus, continuous superior performance for the business." (Narver and Slater 1990, p.21)

"The culture that (1) places the highest priority on the profitable creation and maintenance of superior customer value while considering the interests of other stakeholders; and (2) provides norms for behavior regarding the organizational development of and responsiveness to market information." (Slater and Narver 1995, p. 67).

An organization's superior skills in understanding and satisfying customers' needs, whose principal features are: (1) a set of beliefs that put customers' interest first, (2) the ability to generate, disseminate and use superior information about customers and competitors, and (3) the coordinated application of inter-functional resources to the creation of superior customer value. (Day 1994)

"Market orientation is (1) the systematic gathering of information about customers and competitors, both present and potential, (2) the systematic analysis of information for the purpose of developing market knowledge, and (3) the systematic use of such knowledge to guide strategy recognition, understanding, creation, selection, implementation, and modification." (Hunt and Morgan 1995, p. 11)

\section{Market or Strategic Orientation}

"A multi-dimensional construct that captures an organization's relative emphasis in understanding and managing the environmental forces acting on it. The environmental forces include (1) upstream suppliers of product inputs, including intellectual capital and innovation, (2) downstream customers, and (3) present and potential competitors." (Voss and Voss 2000, p. 68)

\section{Market-Oriented Organizational Culture}

Conceptualized as a construct that includes the four components of (1) organization-wide shared basic values supporting market orientation, (2) organization-wide norms for market orientation, (3) perceptible artifacts of market orientation and (4) the market-oriented behaviors. (Homburg and Pflesser 2000)

\section{Customer Orientation}

"The sufficient understanding of one's target buyers to be able to create value for them continuously." (Narver and Slater 1990, p. 21)

"The set of beliefs that puts the customer interest first, while not excluding those of all other stakeholders such as owners, managers, and employees, in order to develop a long-term profitable enterprise.” (Deshpandé et al. 1993, p. 27)

"The set of behaviors and beliefs that places a priority on customers' interests and continuously creates superior customer value." (Rindfleisch and Moorman 2003, p. 422)

\section{Customer-oriented Firm}

"A firm with the ability and the will to identify, analyze, understand, and answer user needs." (Gatignon and Xuereb 1997, p. 78)

\section{Customer-oriented Selling}

"The extent to which salespeople practice the marketing concept by helping their customers make purchase decisions that will satisfy the customers' needs." (Saxe and Weitz 1982, p. 344)

\section{Competitor Orientation}

A seller's understanding of the short-term strengths and weaknesses and long-term capabilities and strategies of both the key current and the key potential competitors. (Narver and Slater 1990, p. 21-22)

"A firm with the ability and the will to identify, analyze, and respond to competitors" actions." (Gatignon and Xuereb 1997, p. 78)
Construct defined as a firm engaging in specific behaviors organization-wide market intelligence generation, dissemination and responsiveness.

Construct defined as organizational culture that creates specific behaviors.

Construct conceptualized as superior organizational skill.

Reference to the construct as market orientation or strategic orientation implies that these terms can be used interchangeably. However, market orientation and strategic orientation are conceptualized in literature as distinct organizational constructs.

Builds on conceptualization of organizational culture as consisting of four distinguishable but interrelated components - shared basic values, behavioral norms, different types of artifacts and behaviors.

Construct focuses on level of understanding, a precursor for a business to be able to engage in specific behaviors that create value for customer.

Rindfleisch and Moorman (2003, p. 422) note that their definition bridges the views of Narver and Slater (1990, p. 21) and Deshpandé et al. (1993), p. 27) on customer orientation.

Construct defined as a firm engaging in specific behaviors. Definition encompasses both "what is it," and "how much of it is in an object" (i.e., the amount of a specific property or characteristic in an object -- the extent to which salespeople ...).

Construct defined as a firm's ability and will to engage in specific behaviors. 
Table 1 (continued)

\section{Construct: Conceptualization and/or Definition}

Competitor orientation includes the identification and construction of competitive advantages in terms of quality or specific functionalities and enables the firm to position the new product well. A competitor orientation is required for the commercial performance of innovations. (Gatignon and Xuereb 1997)

\section{Technology Orientation}

The firm can use its technical knowledge to build a new technical solution to answer and meet new needs of the users. (Gatignon and Xuereb 1997)

\section{Technology-oriented Firm}

"A firm with the ability and will to acquire a substantial technological background and use it in the development of new products." (Gatignon and Xuereb 1997. P. 78)

\section{Strategic Orientation}

A reflection of a firm's broad strategic choices (Gatignon and Xuereb 1997).

A reflection of the strategic directions implemented by a firm to create the proper behaviors for the continuous superior performance of the business. (Gatignon and Xuereb 1997, p. 78)

A typology for classifying firms as Prospectors, Defenders, Analyzers, or Reactors, based on their pattern of behaviors. Firms whose pattern of behavior evidences a formal and implied strategic orientation are classified as Prospectors, Defenders, or Analyzers. Firms whose pattern of behavior does not evidence a formal strategic orientation are classified as Reactors (Miles and Snow 1978).

Customer orientation, competitor orientation and technological orientation

Three major strategic orientations of the firm can be identified from the list of factors that determine the success of failure of new products. (Gatignon and Xuereb 1997)

\section{Innovation Orientation}

A function of the number of innovations a company offers, how many customers these innovations are offered to, and how strongly these innovations are emphasized. (Homburg et al. 2002)

"A multidimensional knowledge structure composed of a learning philosophy, strategic direction, and trans-functional beliefs that, in turn, guide and direct all organizational strategies and actions, including those embedded in the formal and informal systems, behaviors, competencies, and processes of the firm to promote innovative thinking and facilitate successful development, evolution, and execution of innovations." (Siguaw et al. 2006, p. 560)

\section{Entrepreneurial Orientation}

"A firm-level of predisposition to engage in behaviors (reflecting risk-taking, innovativeness, pro-activeness, autonomy, and competitive aggressiveness) that lead to change in the organization or marketplace.” (Voss et al. 2005, p. 1134)

A set of distinct, but related behaviors that have the qualities of innovativeness, pro-activeness, competitive aggressiveness, risk taking, and autonomy. (Pearce et al. 2010)

\section{Learning Orientation}

The encouragement of organizational values that influence the likelihood of the firm to use and create knowledge. (Sinkula et al. 1997)

\section{Remarks}

Construct defined as a firm's ability to use knowledge to engage in specific behaviors.

Construct conceptualized as a firm engaging in a coherent pattern of behaviors (Prospectors, Defenders and Analyzers), or a set of behaviors that lack coherence (Reactors).

Construct conceptualized as a firm engaging in specific behaviors spanning multiple dimensions.

Construct defined as a firm's predisposition (commitment, inclination, proclivity or tendency) to engage in specific behaviors, as opposed to engaging in specific behaviors.

Construct conceptualized as a firm engaging in certain behaviors in order to create the conditions for it to be able to engage in certain other behaviors.

\footnotetext{
${ }^{a}$ Specific words are italicized in the first column of the table to highlight the frame of reference employed (e.g., behavior, belief, culture, ability and will, understanding) to conceptualize and/or define market orientation and other orientation related organizational constructs. However, they are not italicized in the original sources

${ }^{\mathrm{b}}$ In the doctoral seminar, I have drawn the attention of the students, some of the conceptualizations and definitions of "orientation" centered organizational constructs enumerated in the table, in order to highlight the diverse frames of reference. However, a table such as Table 1 has not been part of the instructional material for the seminar
}

The following are some alternatives definition that I have either proposed in class, or teased from the class:

- "Market orientation refers to an organization's extent of involvement in organization wide generation of market intelligence about customers and competitors, dissemination of the intelligence across departments, and organization wide responsiveness to it."

- “Market orientation refers to an organization's extent of involvement in organization wide generation of 
market intelligence, dissemination of the intelligence across departments, and organization wide responsiveness to it."

In the first of the above definitions, the scope of market intelligence is construed as encompassing intelligence about customers and competitors. In the second definition, the scope of market intelligence is construed even more broadly (as encompassing intelligence about customers, competitors and other entities in the market and aspects of the market). Given that in their definition of market orientation, Kohli and Jaworski (1990) clearly circumscribe the scope of market intelligence as intelligence pertaining to "the current and future needs of customers," the rationale for engaging students in a discussion on alternative definitions of the construct with market intelligence construed more broadly was the following. The learning that could result from engaging students in a discussion and exercise on whether there is potential for improvements in the definition of a construct advanced in the literature, and specific revisions that would constitute improvements ${ }^{5, .6}$

\section{Discussion item \# 3: Behavior based and culture based definitions of market orientation}

Kohli and Jaworski (1990, p.6) define market orientation as "the organization wide generation of market intelligence pertaining to current and future customer needs, dissemination of the intelligence across departments, and organization wide responsiveness to it." Narver and Slater (1990, p.21) define market orientation as "the organizational culture that most effectively and efficiently creates the necessary behaviors for the creation of superior value for buyers and, thus, continuous superior performance for the business." They further note: "We infer from the literature that market orientation consists of three behavioral components - customer orientation, competitor orientation, and inter-functional coordination - and two decision criteria - long-term focus and profitability." Kohli and Jaworski's and Narver and Slater's definitions of

\footnotetext{
${ }^{5}$ In reference to Discussion Item \# 1, in order to initiate a discussion, I would pose a question to the class along the following lines:

Take a look at the author's definition. What does the term "market intelligence" mean to you?

Invariably, some students would allude to market intelligence about competitors (such as planned new product introduction or price reduction), and others to intelligence about customers.

If market intelligence encompasses intelligence about both customers and competitors, how would you revise the definition?

Also, carefully read the second paragraph that follows, which begins with the words, "In other words ..." Take a shot at revising the definition by incorporating a word such as "extent" or "degree" in it, to capture differences in the extent to which organizations are market oriented.

${ }^{6}$ As summarized in Table 1, Hunt and Morgan (1995) conceptualize market orientation as encompassing both market intelligence about present and potential customers, and present and potential competitors.
}

market orientation are generally referred to in literature as behavior based definition and organizational culture based definition, respectively. Given the focus of these definitions on "market intelligence generation, dissemination and responsiveness," and "customer orientation, competitor orientation, and inter-functional coordination," respectively, a question that I have posed to the class for discussion is whether these are indeed definitions of the same organizational construct, or definitions of two distinct organizational constructs (with some conceptual overlap), that are referred to by the same construct label in the literature.

I also reached out to some of my former students for their thoughts on this issue. One of them brought to my attention an article (Homburg and Pflesser 2000), wherein the authors note that while Narver and Slater (1990) define market orientation as an organizational culture, they model it as three behavioral components - customer orientation, competitor orientation and interfunctional coordination. Homburg and Pflesser further note that in the larger body of research based on a cultural definition of market orientation as well, the construct is typically operationalized in terms of behaviors. They surmise that the basic assumption here is that behaviors reflect an underlying organizational culture. Interestingly, Hunt and Morgan (1995, p. 11) note: "As to its ontological status, a market orientation should be considered as an organizing framework that, if adopted and implemented, could through time become culturally embedded in an organization." That is, rather than behaviors reflecting an underlying organizational culture, over time, certain deep rooted behaviors in a firm take shape as organizational culture. ${ }^{7}$

\section{Discussion item \# 4: Adding to the body of knowledge by building on prior research}

Engaging the class in a discussion on how a particular research study builds on prior research studies on the topic, and contributes to accumulation of knowledge on the topic is fairly common in doctoral seminars. For instance, as shown in Fig. 1a, Jaworski and Kohli (1993) investigate the relationship between market orientation [market intelligence generation, dissemination and responsiveness] and business performance, and the moderating effects of market turbulence, technological turbulence, and competitive intensity. Building on prior cross-sectional studies on market orientation, in their cross-sectional and longitudinal study, besides other questions, Kumar et al. (2011) investigate the question of whether over time, market orientation [as defined in Kohli and

\footnotetext{
${ }^{7}$ To date, I have not discussed the issues summarized in this paragraph in the seminar.
} 
Jaworski (1990) and operationalized in Kohli et al. (1993)] transforms from a source of competitive advantage (a success producer) to merely a cost of doing business (a failure preventer) (see Fig. 1b).
Narver and Slater (1990) investigate the relationship between market orientation (customer orientation, competitor orientation and inter-functional coordination) and business performance (see Fig. 1c). Building on Narver and Slater (1990), Han et al.
Fig. 1 Research on Market Orientation: Some Logically Incremental and Comparatively Standalone Research Studies ${ }^{1}$. Fig. 1 is a compilation and adaptation of conceptual models excerpted from some of the assigned readings on market orientation and related topics for the doctoral seminar. Concise adaptations of the models presented in the original sources were drawn on the white board to facilitate class discussion.

However, a comprehensive figure such as Fig. 1 has not been part of the instructional material for the seminar a

Top Mgmt. Factors
. Interdepartmental
Dynamics
. Organizational
Systems

Market Orientation

Market Intelligence (MI) Generation

Organization-wide MI Dissemination

Organizational Responsiveness to MI

Systems

b

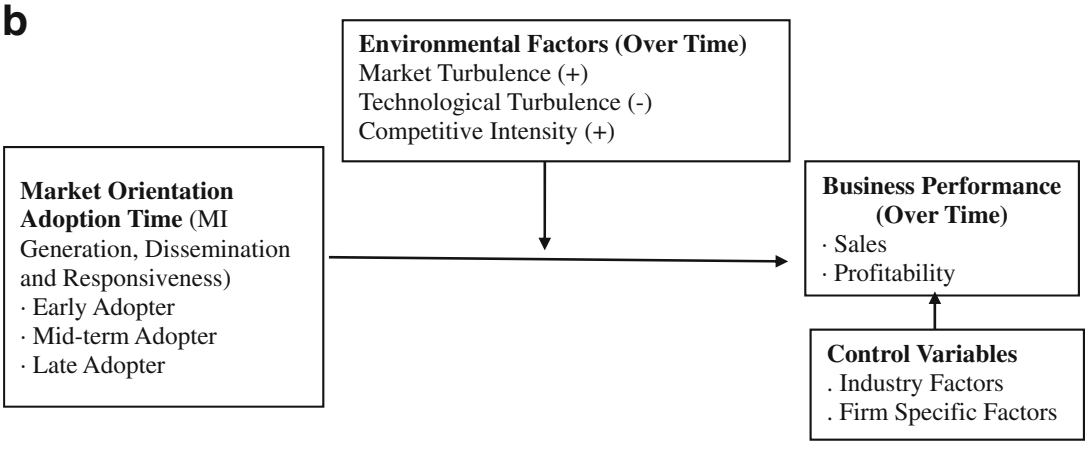

C

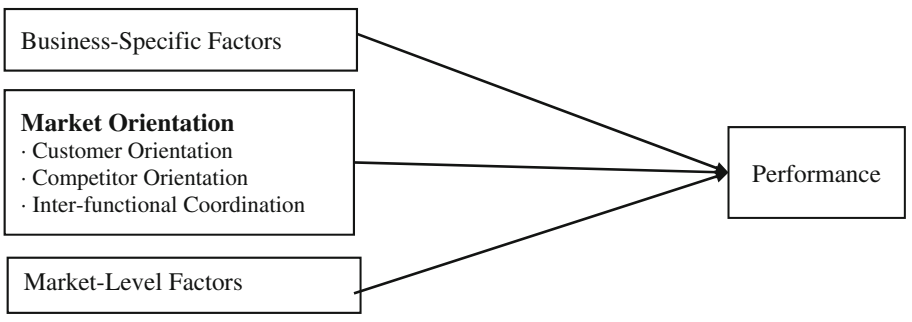

d

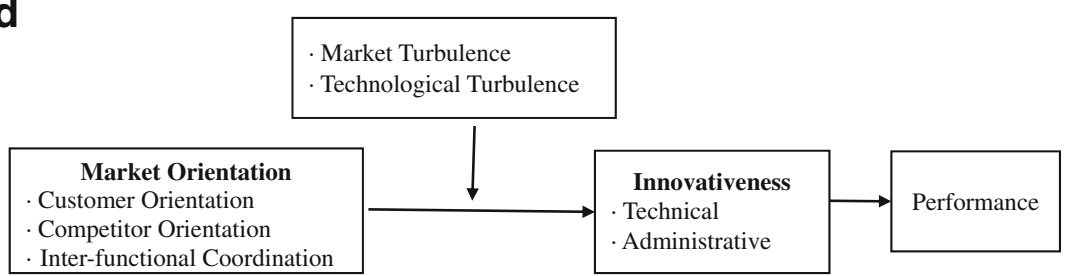

e

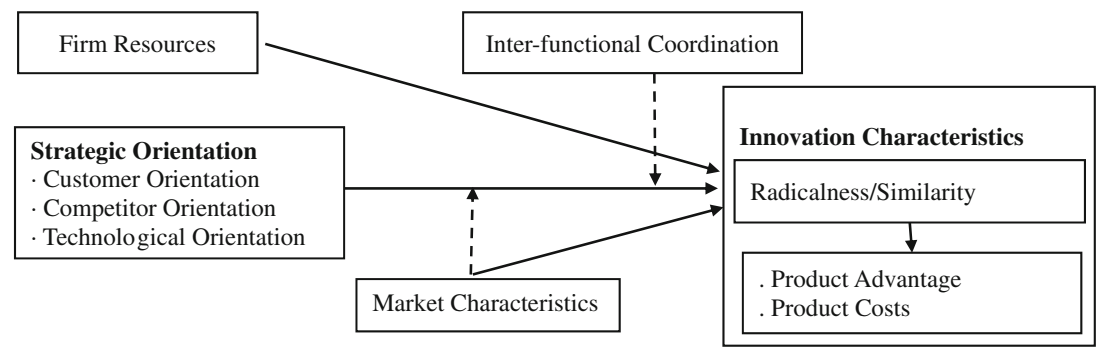


(1998) investigate the mediating effect of innovation on the relationship between market orientation (customer orientation, competitor orientation and inter-functional coordination) and performance, and the moderating effect of market and technological turbulence (see Fig. 1d).

In their study, Gatignon and Xuereb (1997) investigate the relationship between alternative strategic orientations (customer orientation, competitor orientation and technological orientation) and innovation performance, and the moderating effect of inter-functional coordination (see Fig. 1e). While in Narver and Slater (1990), inter-functional coordination is a component of market orientation (see Fig. 1c), in the Gatignon and Xuerb study, inter-functional coordination is modeled as a moderator of the relationship between strategic orientation and innovation performance. Although, Gatignon and Xuerb make extensive reference to prior literature on market orientation, the contribution of their study is essentially to the body of literature on strategic orientation, rather than to the body of literature on market orientation.

\section{Discussion item \# 5: Unit of analysis}

In empirical research on market orientation, the firm as the unit of analysis is appropriate only in the context of single business firms, and not multi-business firms. However, in most parts of the world, the proto-typical large firm (e.g., Fortune 500 firm in the US) is a multi-business firm. For example, the businesses that comprise GE's business portfolio include aviation, energy, healthcare, lighting, oil and gas, power and transportation. In a multi-business firm, customers, competitors, and the external environment (e.g., market environment, technological environment) are specific to individual businesses in the firm's portfolio. For example, firms such as Airbus and Boeing that assemble airplanes, and commercial airlines such as American, Delta and United are among the customers of GE's aviation (jet engines) business unit. Its major competitors are Rolls Royce and Pratt $\&$ Whitney (a business unit of another multi-business firm, United Technologies). The customers served and competitors faced by GE's aviation business unit are totally different from the customers served and competitors faced by its healthcare business unit.

In a multi-business firm, market intelligence generation, dissemination and responsiveness (Kohli and Jaworski 1990) are behaviors at the business unit level (and at lower levels within a business unit, such as product category level), and not at the firm level. Similarly, customer orientation, competitor orientation and inter-functional coordination (Narver and Slater 1990) are at the level of the business unit (and at lower levels within a business unit, such as product category level), and not at the firm level. For these reasons, in the context of multi-business firms, market orientation is a business level construct and not a firm level construct ${ }^{6}$. The appropriate unit of analysis is not the multibusiness firm, but individual businesses in the firm's portfolio.
Marketing performance metrics such as market share and customer satisfaction, and accounting measures of financial performance can be computed at the business unit level (and at lower levels within a business unit, such as the product category level). However, market measures of financial performance, such as Tobin's q, are firm level performance metrics, and therefore are appropriate as a performance measure only in the context of research on market orientation focused on single business firms. Against this backdrop, an issue of concern is research findings reported in market orientation related research studies in which the firm is the unit of analysis. There is often lack of clarity concerning whether the firms studied are single business firms or multi-business firms. If the latter, there is a need for clarity on issues such as whether the study focuses on the largest business unit in the firm as a proxy for the firm, or the responses of various businesses of the firm are weighted and averaged. ${ }^{8}$

\section{Conclusion}

The research, teaching and service (service in roles such as reviewer of manuscripts for journals) of an academician's journey can be mutually reinforcing. In fact, the act of writing and revising (multiple times) this article, and relatedly, selectively reading and reflecting on extant literature on market orientation, has been a source of ideas for some new lessons to share and some new issues to discuss in my seminar, in future years. Case in point is the following.

Relevant literature and/or insights gleaned from business practices in the real world are the basis of definitions of most marketing related organizational constructs. However, the definition of market orientation proposed by Kohli and Jaworski (1990, p. 6) was based on a relatively more exhaustive exercise - a synthesis of insights from field-based, discovery-oriented research and extant literature. This suggests the following potential avenue for future research - a follow-up field-based, discovery-oriented research study to gain insights into marketing practitioners' current views on the meaning of term, "market orientation." In this regard, Jaworski and Kohli (2017) offer valuable guideposts (see: Lessons \# 10 to 16). Also, given the technological advances in the intervening years, it would be feasible to gain insights into marketing managers' contemporary perspectives on the term, "market orientation," employing net-ethnographic methods (see: Kozinets 2002).

\footnotetext{
${ }^{8}$ In reference to the construal of market orientation as organizational culture, it can be argued that culture at the firm level will manifest as market orientation related behaviors in all of the business units of the firm. However, even under such a world-view, there are likely to be differences in the extent of intelligence generation, dissemination across departments and responsiveness (or, customer orientation, competitor orientation and inter-functional coordination) across businesses in a multi-business firm.
} 


\section{References}

Chung, K. H., \& Jang, H. Y. (2003). The effects of internal marketing on market orientation and customer orientation. Journal of Global Academy of Marketing Science, 11(1), 103-128.

Day, G. S. (1994). The capabilities of market-driven organizations. Journal of Marketing, 58, 37-52.

Deshpandé, R., Farley, J. U., \& Webster Jr., F. E. (1993). Corporate culture, customer orientation, and innovativeness in Japanese firms: A quadrad analysis. Journal of Marketing, 57, 23-37.

Gale, B. T. (1994). Managing customer value: Creating quality and service that customers can see. New York: The Free Press.

Gatignon, H., \& Xuereb, J.-M. (1997). Strategic orientation of the firm and new product performance. Journal of Marketing Research, 34, $77-90$.

Graham, J. W., \& Stablein, R. E. (1985). A funny thing happened on the way to publication: Newcomers' perspectives on publishing in the organizational sciences. In cummings, L. L. \& frost, P. J. (Eds.). Publishing in Organizational Sciences, R. D. Irwin, 139-140.

Han, J. K., Kim, N., \& Srivastava, R. K. (1998). Market orientation and organizational performance: Is innovation a missing link? Journal of Marketing, 62, 30-45.

Homburg, C., \& Pflesser, C. (2000). A multiple-layer model of marketoriented organizational culture: Measurement issues and performance outcomes. Journal of Marketing Research, 37, 449-462.

Homburg, C., Hoyer, W. D., \& Fassnacht, M. (2002). Service orientation of a retailer's business strategy: Dimensions, antecedents, and performance outcomes. Journal of Marketing, 66(4), 86-101.

Hunt, S. D. (2012). Explaining empirically successful marketing theories: The inductive realist model, approximate truth, and market orientation. AMS Review, 2(1), 5-18.

Hunt, S., \& Morgan, R. M. (1995). The comparative advantage theory of competition. Journal of Marketing, 59, 1-15.

Jaworski, B. J., \& Kohli, A. K. (1993). Market orientation: Antecedents and consequences. Journal of Marketing, 57, 53-70.

Jaworski, B. J., \& Kohli, A. K. (2017). Conducting field-based, discovery-oriented research: Lessons from our market orientation research experience. AMS Review. doi:10.1007/s13162-017-0088-5.

Kang, S. H., Choi, S. M., \& Park, H. S. (2011). The effect of market orientation on business performance: Focus on mediating role of new product development performance. Yonsei Business Review, $48(1), 1-32$.

Kohli, A. K., \& Jaworski, B. J. (1990). Market orientation: The construct, research propositions, and managerial implications. Journal of Marketing, 54, 1-18.
Kohli, A. K., Jaworski, B. J., \& Kumar, A. (1993). MARKOR: A measure of market orientation. Journal of Marketing Research, 30, 467477.

Kozinets, R. V. (2002). The field behind the screen: Using Netnography for marketing research in online communities. Journal of Marketing Research, 39, 61-72.

Kumar, V., Jones, E., Venkatesan, R., \& Leone, R. P. (2011). Is market orientation a source of sustainable competitive advantage or simply the cost of competing? Journal of Marketing, 75, 16-30.

Merriam-Webster's Collegiate Dictionary. Eleventh Edition. (2003). Merriam-Webster Inc. Springfield: Mass., p. 875.

Miles, R. E., \& Snow, C. C. (1978). Organizational strategy, structure, and process. New York: McGraw-Hill.

Narver, J. C., \& Slater, S. F. (1990). The effect of a market orientation on business profitability. Journal of Marketing, 54, 20-35.

Pearce II, J. A., Fritz, D. A., \& Davis, P. S. (2010). Entrepreneurial orientation and the performance of religious congregations as predicted by rational choice theory. Entrepreneurship Theory and Practice, 34(1), 219-248.

Rindfleisch, A., \& Moorman, C. (2003). Interfirm cooperation and customer orientation (pp. 412-436). XL: Journal of Marketing Research.

Saxe, R., \& Weitz, B. A. (1982). The SOCO scale: A measure of the customer orientation of salespeople. Journal of Marketing Research, 19(3), 343-351.

Shapiro, B. P. (1988). What the hell is "market oriented." Harvard Business Review.

Siguaw, J. A., Simpson, P. M., \& Enz, C. A. (2006). Conceptualizing innovation orientation: A framework for study and integration of innovation research. Journal of Product Innovation Management, 23(6), 556-574.

Sinkula, J. N., Baker, W. E., \& Noordewier, T. (1997). A framework for market-based organizational learning: Linking values, knowledge, and behavior. Journal of the Academy of Marketing Science, 25(4), 305-318.

Slater, S. F., \& Narver, J. C. (1995). Market orientation and the learning organization. Journal of Marketing, 59, 63-74.

The World Book Encyclopedia Dictionary. (1966). C. L. Barnhart (Ed.). Field Enterprises Educational Corporation. Chicago.

Voss, G. B., \& Voss, Z. G. (2000). Strategic orientation and firm performance in an artistic environment. Journal of Marketing, 64(1), 6783.

Voss, Z. G., Voss, G. B., \& Moorman, C. (2005). An empirical examination of the complex relationships between entrepreneurial orientation and stakeholder support. European Journal of Marketing, 39(910), 1132-1150. 